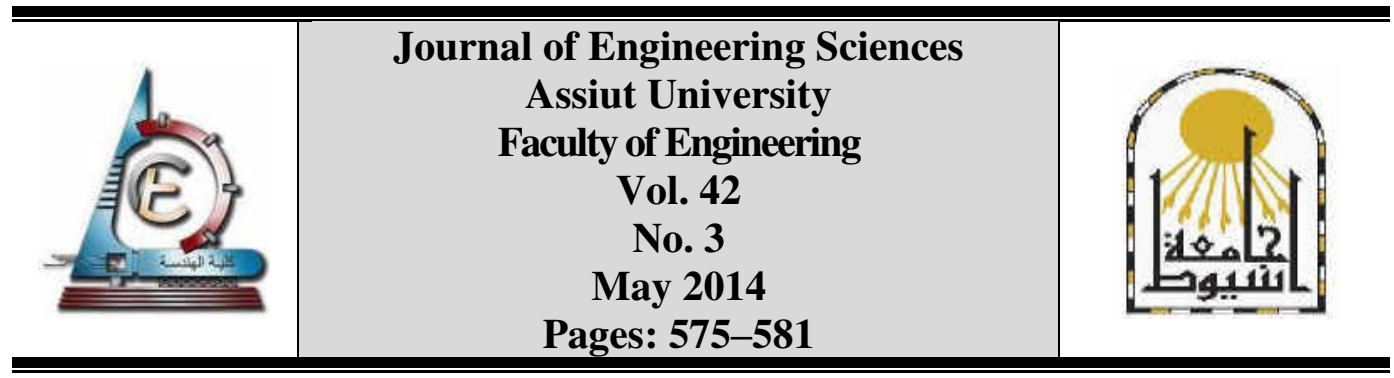

\title{
STUDYING THE EFFECT OF STEEL SLAG POWDER ON MARSHALL STIFFNESS AND TENSILE STRENGTH OF HOT MIX ASPHALT
}

\author{
Afaf A. H. M. \\ Civil Eng. Dep., Faculty of Eng., Minia University
}

Received 17 February 2014; revised 2 March 2014; accepted 10 March 2014

\begin{abstract}
Iron slag powder is a by product that can be obtained during steel manufacturing. Using iron slag powder in road paving can have many environmental advantages such as keeping clean environment and saving natural construction materials. This paper discusses the effect of using iron slag powder on Marshall Stiffness and indirect tensile strength of hot mix asphalt. Three hot mix asphalt with various iron slag contents, namely; $0 \%, 10 \%$ and $20 \%$ by weight of total mixture were studied. Laboratory testing showed an enhancement in different Marshall Properties and indirect tensile strength of hot mix asphalt modified with iron slag. As the iron slag content increases, the Marshall Stability and indirect tensile strength of the studied mixtures increases as well. This is an indication of mixtures performance improvement in addition to the fact that iron slag powder can be used in asphalt paving for environmental advantages.
\end{abstract}

Keywords: Iron slag powder; hot mix asphalt; Marshall/Stiffness, indirect tensile strength.

\section{Introduction}

Many research efforts are being made to study the performance of hot mix asphalt modified with steel slag powder. This can help reducing the pollution of and saving and recycling energies in production process. This slag consists primarily of constituent of the iron ore mixed with the silicates and aluminosilicates of lime and other bases [2]. It is mainly a by-product of iron manufacturing, in which silica and alumina constituents combine with lime to form a molten slag collected on the top of the iron in a blast furnace. The slag issues from the furnace as a molten stream at $1400-1600{ }^{\circ} \mathrm{C}$. Allowing to cool slowly, it solidifies to a grey, crystalline, stone-like material known as air-cooled slag. This product is then crushed and screened to sizes suitable as coarse aggregate. Chemical composition of a slag depends on the composition of the raw materials in the iron production process. The main components of blast furnace slag are $\mathrm{CaO}$ (30-50\%), $\mathrm{SiO} 2$ (28-38\%), Al2O3 (8-24\%), and $\mathrm{MgO}$ (1-18\%).

Improper disposal of slag has become a serious environmental problem [3]. Iron slag can be used in several industrial applications such as glass making, concrete block manufacture, sporting field sub-base (for drainage), filtration medium, reinforced earth embankments, and 
mine backfilling and grit-blasting medium requiring fine etching. Granulated Steel Slag can be ground and used to make slag cement. Compared to regular Portland cement, slag cement provides reduced heat of hydration and improved resistance to sulphate attack and alkalisilica reaction. It is also resistant to chloride penetration, sulphate and thaumasite sulphate attack. It has low risk of thermal cracking and a high electrolytic resistance. Cooling the slag with water produces a lightweight aggregate for use in masonry blocks and lightweight concrete.

Nowadays, many environmental and highway agencies are trying using iron slag in highway construction [4-7]. Iron slag powder can have many advantages over natural powder [8]. It is a durable aggregate that performs well in unbound applications as well as in Portland cement and asphalt concretes. Few research works was made to test the possibility of using iron slag in hot mix asphalt as a replacement of fine aggregates. Having a good friction resistance property it is believed that it can provide an excellent skid resistance asphalt concrete layer surface. The current study is performed to study the effect of using iron slag powder in hot mix asphalt as a part of the fine aggregate. This paper discusses the effect of using iron slag powder on Marshall Stiffness of hot mix asphalt. Three hot mix asphalt with various iron slag contents, namely; $0 \%, 10 \%$ and $20 \%$ by weight of total mixture were studied

\section{Used materials}

Asphalt binder 60/70 was used within this research. The used asphalt binder was subjected to a series of standard laboratory tests to determine its physical properties. Coarse aggregate and fine aggregate (Bulk specific gravity of 2.77 and 2.68 respectively) were used in the preparation of the hot mix asphalt. Limestone was used as mineral filler. The selected gradation of aggregate incorporated in all asphalt concrete specimens confirms to the mid point of the standard 4-c aggregate gradation specified in the Egyptian highway standard specifications. Iron slag powder was crushed and screened to produce aggregate that satisfies the gradation requirements for hot mix asphalt. Table (1) presents the mechanical properties of the used iron slag. As seen, iron slag has favorable mechanical properties for aggregate use, including good abrasion resistance, good soundness characteristics, and high bearing strength. Table (2) presents the gradation of the used steel slag.

Table 1.

Properties of Used Iron slag

\begin{tabular}{|c|c|}
\hline \multicolumn{1}{|c|}{ Property } & Value \\
\hline LAA (\%) & 25 \\
\hline Percent of Soundness Loss & 10 \\
\hline Angle of Friction & $40^{\circ}$ \\
\hline
\end{tabular}

Table 2.

Gradation of Used Iron slag

\begin{tabular}{|c|c|}
\hline \multicolumn{1}{|c|}{ Sieve } & \% Passing \\
\hline \hline No. 50 & 100 \\
\hline No. 100 & 65 \\
\hline No. 200 & 40 \\
\hline
\end{tabular}




\section{Experimental procedure}

\subsection{Sample preparation}

Asphalt percent of 5.5\% was used for all mixtures. Iron slag powder that is used as apart of fine aggregate is blended with the natural aggregate to obtain a uniform iron slag/natural aggregate mix before mixing with the asphalt binder. Four hot mix asphalt with various iron slag contents, namely; $0 \%, 10 \%$ and $20 \%$ by weight of total mixture were prepared in accordance with the Standard 75-blow Marshall design method for designing hot mix asphalt, designated as (ASTM Designation: D 1559-89) [9] using automatic compaction. To provide adequate data three samples were prepared from each mixture for each test.

\subsection{Marshall stiffness test}

The Marshall Stability test (ASTM Designation: D 1559-82), which is one of the most common tests, is used in highway engineering for both mix design and evaluation. Although Marshall Method is essentially empirical, it is useful in comparing mixtures under specific conditions. Therefore it was selected within this research to study the affect of iron slag when added to hot mix asphalt. Maximum value of Marshall Stability was divided by the corresponding flow for each mix to determine Marshall Stiffness value.

\subsection{Indirect tensile strength test}

A mechanical displacement control testing frame was used to conduct the indirect tensile tests in accordance with (ASTM D4123) to evaluate the tensile strength of asphalt concrete mixtures. Test specimens 2.5 inches thick and 4 inches diameter were compacted and then tested using curved steel loading strips 0.5 inch wide. The load was applied at a vertical deformation rate of $4 \mathrm{~mm} / \mathrm{min}$. The indirect tensile strength is the maximum stress developed at the center of the specimen in the radial direction during loading. Two diametrically opposite dial gauges were attached to each specimen at its longitudinal mid-point to measure the diametral (tensile) deformation resulting from the applied loading in an orthogonal direction. This technique can provide an evaluation of the tensile stress-strain characteristics and hence the fracture energy of each mixture can be evaluated. The fracture energy or energy until failure was calculated as the area under the load-vertical deformation curve.

\section{Results and discussion of Marshall/Stiffness factor}

\subsection{Marshall stability}

The results of all Marshall Stability tests using a constant asphalt ratio of 5\% are summarized in Table (3) for mixtures with different iron slag content. All results shown for each specimen are the average value for three tests.

\section{Table 3.}

Marshall Stability Test Results for Mixtures with Different Iron Slag Content

\begin{tabular}{|c|c|c|c|c|c|c|c|}
\hline $\begin{array}{c}\text { Slag } \\
\text { Content as } \\
\% \text { of Total } \\
\text { Mix }\end{array}$ & $\begin{array}{l}\text { Stability } \\
\text { (lbs) }\end{array}$ & $\begin{array}{c}\text { Flow } \\
(0.1 \text { inch })\end{array}$ & $\begin{array}{c}\text { Marshall } \\
\text { Stiffness } \\
\text { (lb/in) }\end{array}$ & VMA \% & Air Voids\% & $\begin{array}{l}\text { Density } \\
\text { (PCF) }\end{array}$ & $\begin{array}{c}\text { Asphalt } \\
\text { Adhesion } \\
\text { With } \\
\text { Aggregate }\end{array}$ \\
\hline $0 \%$ & 1650 & 7 & 2360 & 15 & 4.5 & 144 & Good \\
\hline $10 \%$ & 1805 & 7.5 & 2400 & 17 & 5 & 148 & Good \\
\hline $20 \%$ & 1990 & 7.6 & 2620 & 18 & 6 & 150 & Good \\
\hline
\end{tabular}


It is indicated from Table (3) that Marshall Stiffness value increases as the iron slag content increases. This was also indicated from Figure (1). Thus it can be concluded that, using iron slag enhances the Marshall Stiffness characteristics of hot mix asphalt. This can be attributed to the high frictional resistance of the mixture due to the angular shape and high friction angle $\left(40^{\circ}\right.$ to $\left.45^{\circ}\right)$ of crushed iron slag.

It is also shown in Table (3) that values of Marshall Properties such as, density, air voids ratio and void in mineral aggregate \% increase as well as iron slag content increases. All tested mixtures exhibited good adhesion with used aggregate (including steel slag).

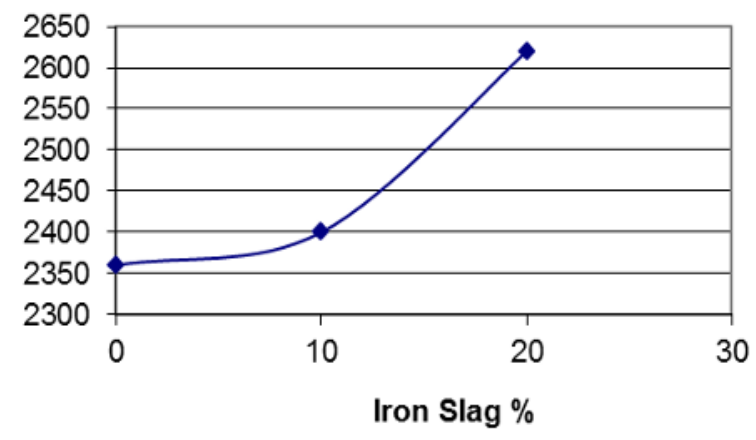

Fig 1. Marshall/Stiffness (lb/in) of Mixtures with Different Iron slag Content

\subsection{Indirect tensile strength}

The indirect tensile test was developed to determine the tensile properties of cylindrical concrete and asphalt concrete specimens through the application of a compression load along a diametrical plane through two opposite loading heads. It was shown [10] that this type of loading produces a relatively uniform stress acting perpendicular to the applied load plane, causing the specimen to fail by splitting along the loaded plane. The expression for the maximum tensile strength can be stated as;

$$
\sigma_{t}=\frac{2 P_{\max }}{\pi D H}
$$

Where $\sigma_{t}$ is the indirect tensile strength, $P_{\max }$ is the maximum applied load and $H, D$ are the thickness and the diameter of the specimen respectively. The indirect tensile strength test was performed on 3 samples from each mixture. Values of indirect tensile strength are calculated based on Equation (1). It is evident from Table (4) that the indirect tensile strength of the iron slag mixtures is almost close to that for mixture without iron slag.

\section{Table 4.}

Indirect Tensile Strength Mixtures with Different Iron Slag Content

\begin{tabular}{|c|c|}
\hline Slag Content as \% of Total Mix & Indirect Tensile Strength (psi) \\
\hline $0 \%$ & 22.40 \\
\hline $10 \%$ & 25.90 \\
\hline $20 \%$ & 27.50 \\
\hline
\end{tabular}

Figure (2) also presents the relation between indirect tensile strength and iron slag content. It is indicated that the indirect tensile strength of the mixtures slightly increases as the slag cont increases. The maximum difference in indirect tensile strength of the 
mixtures is in the range of $7 \%$. Which is considered a very low percent. Thus, it can be stated that the increase in the indirect tensile strength is not significant with the increase in slag content and hence it can be concluded the indirect tensile strength is not sensitive to slag content.

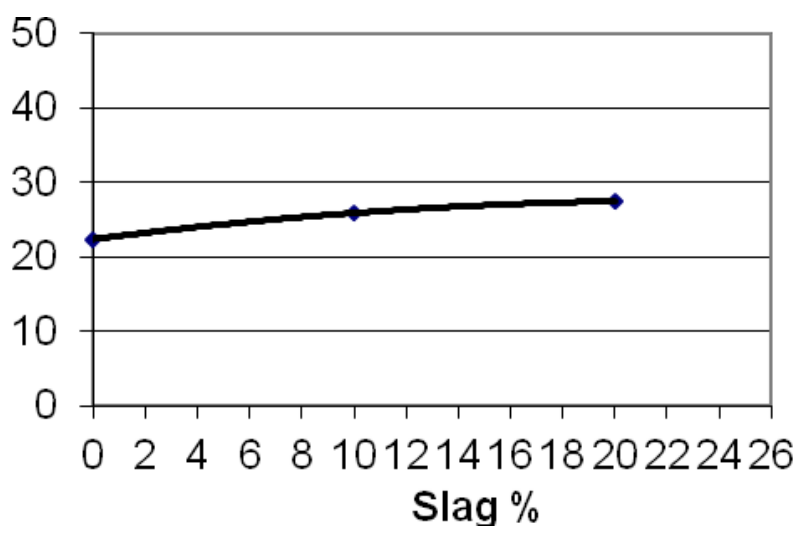

Fig. 2. Indirect Tensile Strength (psi) of Mixtures with Different Iron slag Content

\section{Conclusion and recommendations}

Testing results have shown an improvement in the Marshall stability and the indirect tensile strength when iron slag powder was used in the mixtures as a part of fine aggregate. Within the tested iron slag content range ( $0 \%-20 \%$ of total mixture), the Marshall stability and the indirect tensile strength increase with the increase of iron slag content. It is also evident that values of other Marshall properties such as density, air voids and VMA increased as the steel slag contents increased. More testing is needed to test hot mix asphalt with iron slag content higher than $20 \%$. Generally, iron slag powder can still be used in hot mix asphalt for environmental aspects. All tested mixtures exhibited good adhesion with used aggregate (including steel slag). Before widely adapting iron slag in asphalt paving, trial sections and adequate provisions should be provided.

\section{REFERENCES}

[1] Ahmedzade, P.; Sengoz, B. 2009. Evaluation of steel slag coarse aggregate in hot mix asphalt concrete, Journal of Hazardous Materials 165(1-3): 300-305. http://dx.doi.org/10.1016/j.jhazmat.2008.09.105

[2] Asi, I. M.; Qasrawi, H. Y.; Shalabi, F. I. 2007. Use of steel slag aggregate in asphalt concrete mixes, Canadian Journal of Civil Engineering 34(8): 902-911. http://dx.doi.org/10.1139/107-025

[3] Adel Kurdi, M.El Rafey, R. Abnas , and S.Kandil, " Utilization of Steel-Making Slag in Concrete". Alexandria Engineering Journal, Vol.31, No. 4 October 1992

[4] Chaurand, P.; Rose, J.; Briois, V.; Olivi, L.; Hazemann, J.-L.; Proux, O.; Domas, J.; Bottero J.-Y. 2007. Environmental impacts of steel slag reused in road construction: A crystallographic and molecular (XANES) approach, Journal of Hazardous Materials 139(3): 537-542. http://dx.doi.org/10.1016/j.jhazmat.2006.02.060

[5] Hassan, H. F.; Al-Jabri, K. 2011. Laboratory evaluation of hotmix asphalt concrete containing copper slag aggregate, Journal of Materials in Civil Engineering 23(6): 879-885. http://dx.doi.org/10.1061/(ASCE)MT.1943-5533.0000246

[6] Gupta, J. D., and W. A. Kneller. Precipitate Potential of Highway Subbase Aggregates. Report No. FHWA/OH-94/004, Prepared for the Ohio Department of Transportation, November, 1993. 
[7] GOMAA KH, M.MOUSSA: Use of slag as a base course for flexible pavement" Alexandria Engineering Journal, Vol. 36,No 3,May 1997.

[8] Shatnawi, A. S.; Abdel-Jaber, M. S.; Abdel-Jaber, M. S.; Ramadan, K. Z. 2008. Effect of Jordanian steel blast furnace slag on asphalt concrete hot mixes, Jordan Journal of Civil Engineering 2(3): 197207.

[9] ASTM, “Annual Book pf ASTM Standards: Road Paving, Bituminous Materials, Traveled Surface Characteristics" Part 15, (1982)

[10] Hudson W. R, and Kennedy J. W., "Application of the Indirect Tensile Test to Stabilized Materials". In Highway Research Record 235, HRB, National Research Council, Washington, D. C., 1968 pp. $36-48$. 


\section{دراسة استخدام بودرة الحديد على معامل ثبات مارشال \\ و مقاومة الثد غير المباثر للخلطات الإسفلتية}

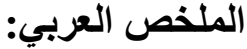

تؤدي الزيادة المطردة في المخلفات الصناعية من المواد الصلبة مثل بودرة الحديد إلى الصى العديد من المشـاكل

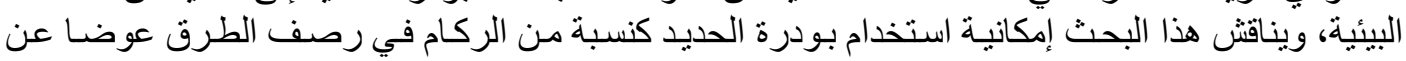

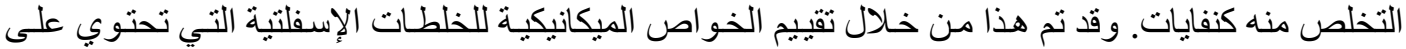

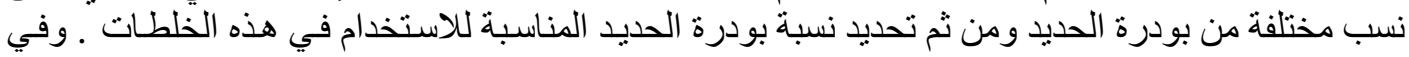

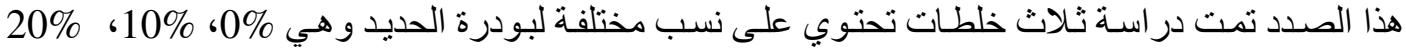

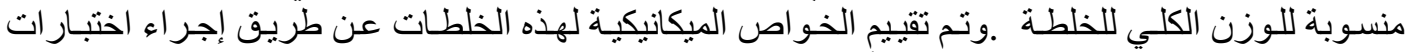

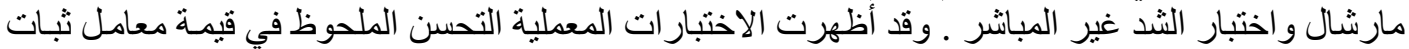

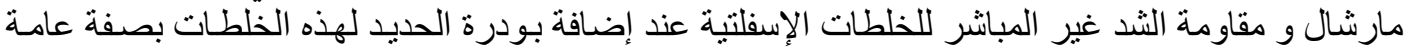

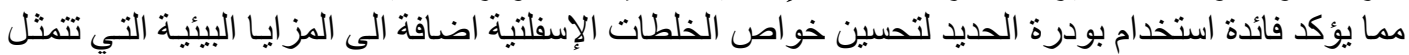
في التخلص الآمن من مو اد ضدارة بالبيئة . 